\title{
Resource Management Schemes for QoS in Hybrid Wireless Networks
}

\author{
Kavita Taneja, PhD. \\ Assoc. Prof., MMICTBM, M.M. University, \\ Mullana, Ambala, Haryana, India
}

\author{
Samriti Setia \\ Research Scholar, M.M. University, \\ Mullana, Ambala, Haryana, India
}

\begin{abstract}
The Hybrid Wireless Network (HWN) such as WLAN, Cellular, ad hoc networks is not only used for transferring voice but also to support data, video and multimedia. In addition, the key issues pertaining to the hybrid networks are managing radio resources, increased successful handover rate and routing management. Although researchers have spent enough time to address the above stated issues however, most of them have remained silent towards the application of related technologies in this domain. One of the technology is agent-based frameworks that serve as a suitable candidate to overcome the above said limitations where, agent-based systems are defined as the cooperative systems where a set of agents acts together to solve a given problem. This paper presents analysis of resource management strategies with Quality of Service (QoS) thus forming a comparison which focuses on limitations pertaining to the existing strategies in HWN.
\end{abstract}

\section{Keywords}

Hybrid Wireless Network (HWN), Resource Allocation, Quality of Service (QoS)

\section{INTRODUCTION}

The issue of providing QoS amongst the integrated wireless environments is highly challenging. Hybrid Wireless Networks are heterogeneous networks with combined medium access methods from cellular, Mobile Ad Hoc Networks (MANET), Internet Protocol (IP) based and 802.1X as shown in figure 1. These networks provides integrated infrastructure with seem less services over several networks as cellular networks provide better QoS as well as reliability due to centralised control on the other hand adhoc networks gives larger coverage, low cost deployment and flexibility [1]. So HWN uses advantages of both the networks but at the cost of increased complexity.

A HWN consists of a large number of micro sensing nodes (SN) capable of sensing, communicating, and actuating are the key elements of WSN. These special nodes are having limited processing and communication capability due to limited energy [16]. The message is sent to the sink or base station (BS) that assembles the report messages received and analyses the event occurrence [2] [3]. The intention is to provide multiple services such as multimedia, multiconnection, multi-party services with different quality-ofservices, enhanced radio bandwidth and seamless user mobility. The large number of users are competing for the resources on the network which are in high demand. Also in

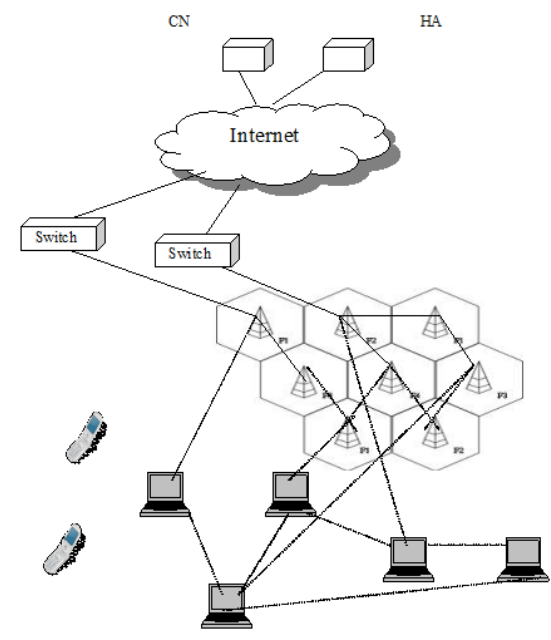

Fig 1:- Hybrid Wireless Network.

Hybrid Wireless Network the requirements for the resources are changing with varying load and radio channel conditions [4]. As a result if the resources are inefficiently allocated it will incur heavy losses to the service providers and will lead to poor user experience. Also the techniques for resource management in one kind of network are different from the other network so resource allocation in HWN is crucial. There have been extensive researches in this field due to system capacity advantage and reasonable infrastructure cost however most of them focus on the infrastructure research but least has been done with service orientation. Also the challenges for communication service have increased as the user demands cost effective service quality with guaranteed QoS. Therefore there is a need for a dynamic resource management system that will maximize network resource utilization with improved QoS. In addition, routing management is another major challenge that is existing due to lack of central control and highly changing nature of the networks especially in case of mobile ad-hoc networks .This paper reviews existing resource allocation schemes thereby exploring the feasibility of finding solutions towards the improvement of QoS in HWN.

User's demand for the enhanced and easily accessible service is the motivation for the evolution of HWN. Upcoming generation wireless networks are desired to be a hybrid of assorted but harmonizing access technologies [16]. One of the application areas of intelligent agent's technology is telecommunication networks [4]. Therefore, the idea of investigating and finding applications of intelligent agent's technology in hybrid wireless networks is still an open challenge. 
The paper is structured as follows: Section 2 describes resource management and quality of Service. Section 3 discuses various resource reservation schemes for better QoS in HWN. Section 4 analyses four resource allocation strategies and forms a comparison study. Finally, paper concludes by discussing the future work in section 5 .

\section{Resource management and QoS}

In hybrid wireless networks to deliver multimedia traffic with quality of services guarantee is a major challenge. Even though the transmission medium is providing abundant bandwidth with cheap QoS support however with advent of new applications there will always be a need of Resource Reservation Schemes with better QoS. QoS for resource reservation scheme has two perspectives one is objective analysis which supports network point of view and other one is subjective analysis which supports application's point of view. In the first resource management refers to the service quality or level that network offers to the users which include delay, jitter, no. of packets lost and throughput. On the other hand in application's view resource reservation refers to the application's quality as viewed by the user that is quality of video, the sound quality of a streaming audio etc [15].

Resource management has two basic elements in QoS which are vertical and horizontal. Vertical QoS defines intra domain QoS which is not complex as the resources are managed by a single entity or a set of entities supporting a common protocol. Here each network layer has different QoS parameters. In horizontal QoS has inter domain QoS which is formed by interconnecting several intra domain schemes.

\section{Resource management schemes with better QoS}

With the growth of new technologies in mobile wireless networks new and better QoS is a challenge with mobile users as compared to the stationary users. Resource management is crucial in wireless networks with user mobility as when user moves from one cell to another, resources that are available in one cell might not be available in other cells thus demanding resource reservation schemes in advance that are adequate and quick[9]. When the QoS is not affected by the user's movement it is called mobile independent service. On the other hand Mobile dependent service is one where QoS varies and may sometimes decrease [10] [11]. For these kinds of services we have various schemes as follows.

A proactive approach is the one where we reserve some amount of bandwidth in advance so that QoS does not decrease when the user is mobile [11-14]. With static schemes it poses great problem as we have to reserve the bandwidth in every cell the user is going to proceed, which is difficult to identify and if we reserve bandwidth for all the cells it leads to underutilization of a network. Dynamic approach tried to predict the cell in advance and reserve bandwidth leading to network utilization but sometimes it does not guarantee to do so due to shortage of resources [10].

A reactive approach is the one that allocate bandwidth on demand. Reservation is done only in the first cell and further bandwidth is rearranged. If there is not suitable bandwidth then when the user goes to a new cell it is equally divided within all the sessions thus satisfying the minimum QoS requirements for all the users of a given cell [9].

Hybrid system is the one that combines both the above mentioned schemes with a call admission control and resource configuration strategy for flexible QoS management. As the handoff is more important than new calls also different traffic classes have priorities as real time traffic is having higher priority than others so in case of inadequate bandwidth the higher priority class can borrow resources from lower priority class .Also one class traffic can borrow resources from current class traffic in the target cell where it is going to move into. Figure 2 describes the above mentioned schemes with their advantages and limitations.

\begin{tabular}{l|l|l|}
\hline Resource reservation Schemes & Advantage & Limitation \\
\hline Static proactive scheme[10] & $\begin{array}{l}\text { It is simple but least complexity } \\
\text { as bandwidth reservation is done }\end{array}$ & $\begin{array}{l}\text { Bandwidth reservation in } \\
\text { advance causes network } \\
\text { underutilization. }\end{array}$ \\
\hline Dynamic proactive scheme[9] & $\begin{array}{l}\text { Reserve bandwidth for some cell } \\
\text { and not for all leading to networ } \\
\text { utilization. }\end{array}$ & $\begin{array}{l}\text { Does not guarantee QoS } \\
\text { due to limited network } \\
\text { resources. }\end{array}$ \\
\hline Reactive approach[8] & $\begin{array}{l}\text { It performs bandwidth reservatio } \\
\text { when the session is initiated and } \\
\text { bandwidth allocation when } \\
\text { necessary. }\end{array}$ & $\begin{array}{l}\text { adequate it leads to } \\
\text { session ending thus } \\
\text { compromising QoS. }\end{array}$ \\
\hline Hybrid approach[8] & $\begin{array}{l}\text { It balances proactive and reactiv } \\
\text { scheme with a call admission } \\
\text { control mechanism. }\end{array}$ & Increased complexity \\
\hline
\end{tabular}

Fig 2: Resource Reservation Schemes advantages and limitations.

\section{Resource Allocation Management Schemes}

In any network, traditional processing of packets occurs in a static way through predefined instructions used in configuration of network devices. This leads to passive networks posing difficulties in integrating new technologies and standards into the shared network infrastructure which in turn demands for the substitution of devices or their reconfiguration by network, administration, poor performance due to redundant operations at several protocol layers and unable to accommodate new services in the existing design. So there comes Active networks with routers and switches which can perform computations on the flowing user data along with dynamic programs thus satisfying the application's needs in execution. Since then, various strategies for resource allocation management have been worked upon [5], [6] and [7]. Four different strategies are compared here. The working of these strategies is beyond the scope of this paper and one can refer to the literature. Since in wireless networks the traffic characteristics and QoS needs are not known in advance, also they may differ in the amount of resources required so the network should dynamically adapt him self for the reservation of the resources for handoffs. With user mobility the new cell must guarantee the QoS requirements by providing sufficient resources to the handoff calls. This can be done if cell reserve resources in advance in the form of guard channels. These strategies differ in calculating the threshold values by the base station.

The strategies compared are:-

A) Fixed Strategy[4]

In this strategy a fixed amount of capacity of base station is reserved for handoffs as a guard threshold. Also the QoS needs of handoffs are fulfilled if the percentage is high thus compromising new connections. Its advantage is its simplicity however it is not directly based on the effective bandwidth of the connection requests. 


\section{B) Static Strategy[6]}

This strategy is cohering of the effective bandwidths of the handoffs requests. Here the base station is aware of the connection requests determined from the historic traffic information which the previous strategy was lacking but both the strategies do not use any dynamic information.

\section{C) YL97 Strategy[8]}

In this strategy each base station dynamically adapt the capacity reserved for dealing handoffs requests based on the current connections in the neighboring cells. This will not waste the resources by reserving only the actual ones needed for handoffs and thereby can accept more new connection requests as compared to the earlier two schemes.

\section{D) Expected Max Strategy[8]}

This strategy extends the YL97 strategy for dealing with multiple traffic classes. Here an estimate of the rate at which handoff connection requests are expected to arrive in the next update period is calculated by each base station. Also the new connection are estimated and then the model studies these probabilities as the function of guard channels and computes the minimum number of them to meet the target blocking probability for handoff requests.

The comparison of these four strategies is done in figure 3 for different types of networks. The performance measure is the blocking probability for handoffs and new connections.

\begin{tabular}{c|l|l|l|l|l|l|}
\hline \multirow{2}{*}{} & \multicolumn{5}{|c|}{ Blocking Probability as the function of load } \\
\cline { 2 - 7 } & \multicolumn{2}{|c|}{ Low load } & \multicolumn{2}{c|}{ Medium load } & \multicolumn{2}{c|}{ High load } \\
\cline { 2 - 7 } & Handoff & $\begin{array}{c}\text { New } \\
\text { Connection }\end{array}$ & Handoff & $\begin{array}{c}\text { New } \\
\text { Connection }\end{array}$ & Handoff & $\begin{array}{c}\text { New } \\
\text { Connection }\end{array}$ \\
\hline Fixed & $\begin{array}{l}\text { Above } \\
\text { average }\end{array}$ & $\begin{array}{l}\text { Above } \\
\text { average }\end{array}$ & $\begin{array}{l}\text { Above } \\
\text { average }\end{array}$ & $\begin{array}{l}\text { Above } \\
\text { average }\end{array}$ & $\begin{array}{l}\text { Above } \\
\text { average }\end{array}$ & $\begin{array}{l}\text { One of } \\
\text { the best }\end{array}$ \\
\hline Static & Average & Average & Average & Average & Average & $\begin{array}{l}\text { Above } \\
\text { average }\end{array}$ \\
\hline YL97 & Worst & $\begin{array}{l}\text { One of } \\
\text { the best }\end{array}$ & Worst & $\begin{array}{l}\text { One of } \\
\text { the best }\end{array}$ & Worst & Average \\
\hline $\begin{array}{c}\text { Expected } \\
\text { Max }\end{array}$ & $\begin{array}{l}\text { One of } \\
\text { the best }\end{array}$ & Worst & $\begin{array}{l}\text { One of } \\
\text { the best }\end{array}$ & Worst & $\begin{array}{l}\text { One of the } \\
\text { best }\end{array}$ & Worst \\
\hline
\end{tabular}

Fig 3: Comparative study of the Blocking probabilities for various Resource management strategies.

From the above figure we conclude that the Expected Max strategy in [8] has lower handoff blocking probability than all other schemes which are better for new connection blocking probabilities. Also the YL97 strategy shows poor performance as compared to the Fixed strategy and the Static scheme for handoff blocking probabilities. There exists a trade off between blocking probability of handoff and new connection. As we tend to decrease blocking probability of handoff the blocking of new connection increases.

\section{Conclusions and future work}

For proper implementation of hybrid wireless networks an improvement in QoS i.e. increased bandwidth, minimal computation overhead, increased throughput, decreased dropping rate and blocking probability and improved routing algorithms are needed. Existing resource management strategies for HWN are explored. This paper presents a comparative study of the blocking probabilities for four major resource management schemes. The Expected Max strategy achieves lower handoff blocking probability than all other schemes. Also the Fixed, Static and YL97 strategy shows good performance for new connection blocking probabilities.
So we require Resource management schemes that tend to decrease blocking probability of handoff and new connection thereby providing better QoS. Further study will proceed in the interest of exploring the feasibility of swarm intelligence for effective resource management in HWN.

\section{References}

[1] Hongxiang Li; Weiyi Zhang; Vanteru, S, "OFDMA Resource Allocation and QoS Provision in Hybrid Wireless Network," Vehicular Technology Conference (VTC 2010-Spring), 2010 IEEE 71st, Issue Date: 16-19 May 2010, pp.1-5.

[2] J. Kahn, R. Katz, K. Pister. "Next Century challenges: Mobile Networking for Smart Dust". ACM MobiCom '99 Washington 1999; 271-278.

[3] A. Cerpa, J. Elson, D. Estrin, L.Girod, M. Hamilton and J.Zhao, "Habitat Monitoring Application Driver for Wireless Communication Technology." ACM SIGCOMM Workshop on Data Communications in Latin America and the Caribbean Costa rica, 2001; 3-5.

[4] Babbar, R. Fapojuwo, A.O. Far, B.H.,"Agent-based resource management in hybrid wireless networks", "Electronics and Computer Engineering Canadian Conference", May 2004, Vol.3, pp: 1297- 1300.

[5] A. I. Elwalid and D. Mitra, "Effective bandwidth of general Markovian traffic sources and admission control of high-speed networks," IEEE/ACM Trans. Networking, June 1993, Vol. 1, pp. 329-343.

[6] R. Guerin, H. Ahmadi, and M. Naghshineh, "Equivalent capacity and its application to bandwidth allocation in high-speed networks," IEEE J. Select. Areas Comm., Sept 1991, Vol. 9, pp. 968-981.

[7] F. P. Kelly," Effective bandwidths at multi-type queues", Queueing Syst., 1991, Vol. 9, pp. 5-15.

[8] Parameswaran, M. Krishna, Sivalingam, "Dynamic Resource Allocation Schemes during Handoff for Mobile Multimedia Wireless Networks", IEEE, July 1999, Vol. 17, No. 7

[9] Jian Ye; Papavassiliou, S.; Anastasi, G.; Puliafito, A. Computers and Communications, 2002. Proceedings. ISCC 2002. Seventh International Symposium on Digital Object Identifier: 10.1109/ISCC.2002.1021703 Publication Year: 2002, Page(s): 369 - 374 IEEE CONFERENCE PUBLICATIONS

[10] S.Lu, K.W.Lee and V.bharghavan, "Adaptive service in Mobile Computing Environments", Proc. IFIP Int'l Workshop on QoS, 1997.

[11] A. K. Talukdar, B. R. Badrinath, A. Acharia, "Integrated Services Packet Networks with Mobile Hosts: Architecture and Performance", Wireless Networks, 1999, Vol. 5, N.2.

[12] D.A.Levine, I.F.Akylidiz and M.Naghshineh, "A Resource Estimation and Call Admission Algorithm for Wireless Multimedia Networks Using the Shadow Cluster Concept".IEEElACM Trans. on Networking, Feb 1997, Vol.5, No.1.

[13] M.Naghshineh and M.Schwartz, "Distributed Call Admission Control in Mobile/Wireless Networks", IEEE J-SAC, May 1996, Vol.1 4, No.4. 
[14] C.Oliveira, J.B.Kim and T.Suda, "An Adaptive Bandwidth Reservation Scheme for High-Speed Multimedia Wireless Network", IEEE J-SAC, Aug 1998, Vol. 16, No.6, pp. 85'8-874.

[15] C.R. Kube and H. Zhang, "Stagnation recovery behaviors for collective robotics," Proc. IEEE/RSJ/GI International Conf. on Intelligent Robots and Systems, 1994, Vol. 3, pp. $1883-1890$.
[16] Dr. Kavita Taneja, Dr. Harmunish Taneja, Shelja Ganesh, "Computing Issues in Hybrid Wireless Networks", International Journal of Applied Engineering Research, Nov 2012, Vol. 7, No. 11, pp. 2113-2115. 